\title{
11 Future Research in Agile Systems Development: Applying Open Innovation Principles Within the Agile Organisation
}

\author{
Kieran Conboy, Lorraine Morgan
}

\begin{abstract}
A particular strength of agile approaches is that they move away from 'introverted' development and intimately involve the customer in all areas of development, supposedly leading to the development of a more innovative and hence more valuable information system. However, we argue that a single customer representative is too narrow a focus to adopt and that involvement of stakeholders beyond the software development itself is still often quite weak and in some cases non-existent. In response, we argue that current thinking regarding innovation in agile development needs to be extended to include multiple stakeholders outside the business unit. This paper explores the intra-organisational applicability and implications of open innovation in agile systems development. Additionally, it argues for a different perspective of project management that includes collaboration and knowledge-sharing with other business units, customers, partners, and other relevant stakeholders pertinent to the business success of an organisation, thus embracing open innovation principles.
\end{abstract}

\subsection{Introduction}

The last 10 years or so has seen the emergence of a number of agile systems development (ASD) methods, such as XP (Beck, 1999) and Scrum (Schwaber \& Beedle 2002). These methods have been well received by those in ISD and there is strong anecdotal evidence to suggest that awareness and indeed use of these methods is highly prevalent across the community. However, some reports have heavily criticised what agile research exists (e.g. Dybå and Dingsøyr 2008; Abrahamsson et al. 2009; Conboy 2009). These reports accuse the current body of agile method research of lacking rigor, cumulative tradition and sufficient theoretical grounding. They even point to the ambiguity as to what constitutes 'agility', stating that it "now means so many things to so many people, it has lost a lot of its meaning" (Conboy 2009).

A particular strength of agile approaches is that they move away from 'introverted' development where the team building the system are detached from the customer. Instead, agile approaches continually involve the customer in the development process, supposedly leading to the development of a more innovative and hence more valuable information system (Beck 1999; Schwaber \& Beedle 2002). However, while the customer plays an essential part in the agile process, this practice could be extended to include multiple stakeholders and even other organisa- 
tions. We propose that it is useful to consider how the agile innovation process can benefit from becoming more 'open', e.g., by opening up the boundaries of a systems development entity to include other stakeholders besides the customer. For example, it has been suggested that companies must increasingly work with each other to enhance their agility in adapting to market developments and developing new products/services cheaper and faster (Tapscott and Williams 2005).

As far as we are aware, no research has focused on the role of other stakeholders in agile development besides the customer. Nor has research looked at how principles of open innovation could complement an agile approach, despite the commonalities between the two models, particularly its emphasis on the value of people and communications. In addition, there is no research that we know of that investigates the implications of a more open approach for project management. Furthermore, there is no research that examines the development of appropriate and effective project management practices to support high quality open innovation in agile information systems development. Thus, exploring the notion of open innovation and its applicability and implications in a multiple project environment that employ agile methods is timely.

The remainder of the paper is structured as follows. The next section presents the current state of research on innovation in agile development. Next, some contemporary views on innovation are described. A conceptual framework to discuss future research is then put forth, followed by some conclusions.

\subsection{Innovation in Agile Development - The Current State of Research}

Innovation and creativity have been advocated as a core part of Information Systems Development (ISD) for many years (Brooks 1987; Elam and Mead 1987; Cougar 1990; Sampler and Galleta 1991; Lobert and Dologite 1994; Gallivan 2003; Carayannis and Coleman 2005). According to Sternberg and Lubart (1999), creativity is the ability to produce work that is considered novel, appropriate and adaptive. Indeed Cougar (1990) believed that creative activities should play a pivotal role "in all aspects of IT development, from requirements definition through program design". Three reasons have been proposed for this. Firstly, "technology is evolving on a daily basis and we can continually look for new ways to utilise resources". Secondly, "most simple systems have already been developed and the challenging ones are still ahead". Finally, "many information systems are old, not meeting existing demand, and will soon become obsolete" (Lobert and Dologite 1994). In addition researchers such as Gallivan (2003) highlight the importance of creative developers, and Brooks (1987) even contends that the critical problems in ISD may not be addressed by ISD methods per se, but rather by how those methods facilitate creativity and improvisation. The importance of creativity has also been highlighted and the support towards creativity claimed within the agile 
method movement (Highsmith and Cockburn 2001; Cockburn and Highsmith 2001; Highsmith 2002; Highsmith 2002a; Highsmith 2004). Agile advocates believe that "creativity, not voluminous written rules, is the only way to manage complex software development problems" (Highsmith and Cockburn 2001). Cockburn and Highsmith (2001) also claim that "agile methodologies deal with unpredictability by relying on people and their creativity rather than on processes". Additionally, it has been contended that "agile approaches are best employed to explore new ground and to power teams for which innovation and creativity are paramount" (Highsmith 2002a). The literature also illustrates the fact that the requirement for creativity has been highlighted in discussions of specific agile methods, such as eXtreme Programming (XP), one of the most popular agile methods (Highsmith 2002a; Crispin and House 2003; Benediktsson et al. 2004). Highsmith (2002a) obscrvers that "although XP contains certain disciplined practices, its intent is to foster creativity and communication". Indeed, Benediktsson et al. (2004) claim that "given the benefits of XP in terms of creativity, value delivery and higher satisfaction levels, it is not surprising that many managers and developers have adopted such practices".

Despite these claims, however, there is a lack of understanding of what constitutes creativity and innovation in software development in general and to what extent agile methods actually facilitate these processes.

\subsection{Contemporary Thinking on Innovation - Open Innovation}

Innovation is now viewed as the lifeblood of organizations that want to survive and prosper in a marketplace that is global in nature and intensely competitive. However, this particular stance on the importance of innovation did not always exist. Traditionally, the innovation process has taken a linear approach, the expectation being that investment in research and development will provide organisations with a competitive advantage (Kane and Ragsdell 2003). In addition, conventional approaches to innovation assumed that it was the experts 'within' the company that invented and designed innovative new products to meet customer needs and organisations rarely looked outside for new ideas or inventions (Tapscott and Wi1liams 2005). As Hamel and Prahalad (1990) pointed out, "organizations often tend to be hidebound and so orthodox ridden, "that the only way to innovate is to put a few bright people in a dark room, poor in some money, and hope that something wonderful will happen" (p. 66). This 'Silicon Valley' approach resulted in innovation being an isolated activity where growth depended on the inventive capacity of individuals and small teams (Hamel and Prahalad 1990). Thus, this very approach in which organisations generate, develop and commercialise their own ideas belong to the closed model of innovation (Fasnacht 2009).

Closed innovation is a view that successful innovation requires control and that firms need to be strongly self-reliant because of uncertainty with quality, availabil- 
ity and capability of others' ideas (Chesbrough 2003). Traditionally, new business development processes and the marketing of new products took place within the firm boundaries and exclusively with internal resources. Within the closed model, the innovation process is characterised by firms that invest in their own $R \& D$, employing smart and talented people in order to outperform their competitors in new product and service development. In addition, after producing a stream of new ideas and inventions, firms must defend their intellectual property thoroughly against the competition (Dahlander and Gann 2007). Changes in society and industry, however, have led to an increased availability and mobility of knowledge workers and the development of new financial structures like venture capitalism. Indeed, Gassmann and Enkel (2004) propose that shorter innovation cycles, industrial research and the rising costs of development, in addition to a lack of resources are motives that are changing companies' innovation strategies towards a more open direction (Gassman and Enkel 2004).

It has been argued that a paradigm shift is taking place in how companies commercialise knowledge, resulting in the boundaries of a firm eroding. This has been characterised as a move towards 'Open Innovation', a paradigm viewed as the antithesis of the traditional model of innovation where research and development activities lead to internally developed products that were then distributed by the firm (Chesbrough et al. 2006). A general theme underling open innovation is that firms cannot continue to look inward in their innovation processes, isolating themselves from possible partners, collaborators and competitors. In other words, open innovation invites firms to open up their boundaries to achieve a flexible and agile environment. The term 'open innovation' has been defined by West and Gallagher (2006, p.82) "as systematically encouraging and exploring a wide range of internal and external sources for innovation opportunities, consciously integrating that exploration with firms capabilities and resources and broadly exploiting those opportunities through multiple channels". In addition, Laursen and Salter (2006) focused on external search breadth and external search depth for different types of innovation in a large-scale sample of UK manufacturing firms. These authors defined openness as "the number of different sources of external knowledge that each firm draws upon in its innovative activities" (2004, p.1204). In contrast to the linear closed model of innovation, the open innovation approach suggests that firms develop processes to ensure a flow of ideas across its boundaries because not all smart people work for the organisation and there is an increasing geographical dispersion of knowledge (Dahlander and Gann 2007). Thus, ideal business search outside their own companies for the best ideas, seeking input from other companies, which include competitors, as well as from customers, suppliers and vendors. 


\subsection{Project Management in An Open Agile Environment}

In an agile development environment, the project manager's role is greatly changed, and is more akin to that of a facilitator or coordinator (Alleman 2002; Lindstrom \& Jeffries 2004; Nerur et al. 2005). In agile projects, the organisation or team structure is "organic and flexible", as opposed to traditional structures which are "mechanistic, bureaucratic and formalized" (Nerur et al. 2005); the method is there not as a prescription, but something to be continuously tailored and moulded by the team (Fitzgerald et al. 2006; Conboy and Fitzgerald 2009); the project is completed through a series of iterations, each often as short as a few working days (Fowler \& Highsmith 2001; Fitzgerald et al. 2006), resulting in more frequent, short-term development; budgeting is more fluid and short term (Conboy 2010), and software is valued over documentation (Fowler \& Highsmith 2001). Significantly, the customer plays a more continuous and embedded role, and thus is intrinsically involved in most project management decisions (Beck 2000; Griffin 2001; Farell et al. 2002; Beck \& Andres 2004). Moreover, developers are not confined to a specific specialised role and are encouraged to selforganise, interchanging and blending roles (Nerur et al. 2005) and become involved in project management issues that may fall outside their traditional skill areas.

However, the very concept of incorporating open innovation principles may prove challenging for an agile project manager. As well as coping with managing in such a fluid, short-term environment, dealing with multiple projects and external entities adds further challenges and risk of unexpected outcomes. However, mechanisms for scanning the project landscape need to be incorporated into project management practices in agile organisations and project managers need to be aware that an IS project is no longer a local matter that can be treated as a closed innovation isolated from the rest of the organisation. After all, it has been found that project boundaries are pliable and negotiable and a project should be seen in light of other projects within an organisation. Indeed, knowledge in and about projects should be exchanged and individual projects should scan the open space of the organisation for other projects that constitute potential collaboration (E1banna 2008). Thus, taking an open innovation route may present many additional benefits for an agile environment.

\subsection{Conceptual Framework to Guide Future Research}

For our theoretical base, we propose a framework drawn from three central open innovation archetypes proposed by Gassmann and Enkel (2004). These include: (1) the outside-in process; (2) the inside-out process; and (3) the coupled process. This framework provides a useful lens to examine the applicability of open innovation in a multiple-project agile environment and the challenges and implications 
of such an approach for project management. Open innovation can be analysed at a number of levels, which include the intra-organisational and inter-organisaional networking level (Chesbrough et al. 2006). However most existing research on the phenomenon of open innovation focuses on inter-organisational aspects. In contrast, the implications that open innnovation has within an organisation and in particular the fact that it affects different parts of an organisation differently are largely neglected in the current literature (Alexy and Henkel 2009). While there exists much research about intra-organisational level networking in general to stimulate innovation (e.g., Tsai and Ghoshal 1998; Foss and Pedersen 2002; Lagerstrom and Andersson 2003), this type of networking has not been analysed explicitly within the open innovation context (Vanhaverbeke 2006). In particular, there is no research that we know of that addresses intra-organisational networking in an agile project environment. In order to address this, we have tailored Gassmann and Enkel's framework to include innovation that occurs outside the boundaries of a business unit rather than outside a firm per se.

\subsubsection{The Outside-in Process}

Companies that decide on an outside-in process as a core open innovation approach choose to cooperate with suppliers, customers third parties etc. and integrate the external knowledge gained. This can be achieved by investing in global knowledge creation, applying innovation across industries, customer and supplier integration and purchasing intellectual property. IBM has been cited by Gassmann and Enkel (2004) as one company that invests substantially in contact with customers and other external knowledge sources while CISCO is another that invests in young start-up companies in order to monitor their attractiveness and innovativeness. According to Gassmann and Enkel (2004), if firms possess the necessary competencies and capabilities, they can successfully integrate internal company resources with the critical resources of other members such as customers, suppliers etc, by extending new product development across organizational boundaries. As the focus of this research in on open innovation at the intra-organisational level, an outside-in open innovation approach will refer to the integration of external knowledge and resources gained from multiple stakeholders outside the business unit.

\subsubsection{The Inside-out Process}

This process focuses on the externalising of company knowledge and innovation in order to bring ideas to market faster. This approach includes licensing IP or multiplying technology by transferring ideas to other companies. Additionally, focussing on an inside-out proces by commercialising ideas to different industries can increase a company's revenue base substantially. For example, companies 
like Novartis, Pfizer and Roche are well recognised for developing substances that were originally aimed at treating one ailment but became better known when used for others. One example of this is Viagra, initially developed to control blood pressure but became more successful as a sexual aid (Gassman and Enkel 2004). Outsourcing has been recognized as one mechanism that can also be used to channel knowledge and ideas to the external environment. The benefits of outsourcing include gaining access to new areas of complementary knowledge, managing capacity problems which allows for more flexibility, reduced time-to-market, sharing of costs and concentration of core competencies It has been found that companies that choose an inside-out process are mainly research-driven companies like IBM, Pfizer or Novartis. Such companies aim to decrease their fixed costs of $\mathrm{R} \& \mathrm{D}$ and share the risks by outsourcing part of their development process (Gassmann and Enkel 2004). In the context of this study, an inside-out process refers to leveraging and transferring knowledge to stakeholders outside the boundaries of a business unit and gaining certain advantages by letting ideas flow to the outside.

\subsubsection{The Coupled Process}

This open innovation approach combines the outside-in (gaining external knowledge) with the inside-out process (to bring ideas to market). In order to accomplish both, these companies collaborate and cooperate with other companies (e.g. strategic alliances, joint ventures), suppliers and customers, as well as universities and research institutes.

Alliances with complementary partners can lead to the occurrence of cooperative innovation processes, e.g. Canon and HP joined forces to develop printers while Boeing developed the Boeing 777 with companies in seven different countries. To collaborate and cooperate successfully, a give and take of knowledge approach is crucial. Benefits of such an approach include an intensive exchange of knowledge and a mutual learning process (Gassmann and Enkel 2004). In this research, a coupled process will also refer to a combination of outside-in and inside-out as specified for this study. In particular, how business units cooperate and interact with other business units in intra-organisational networks will be explored. 


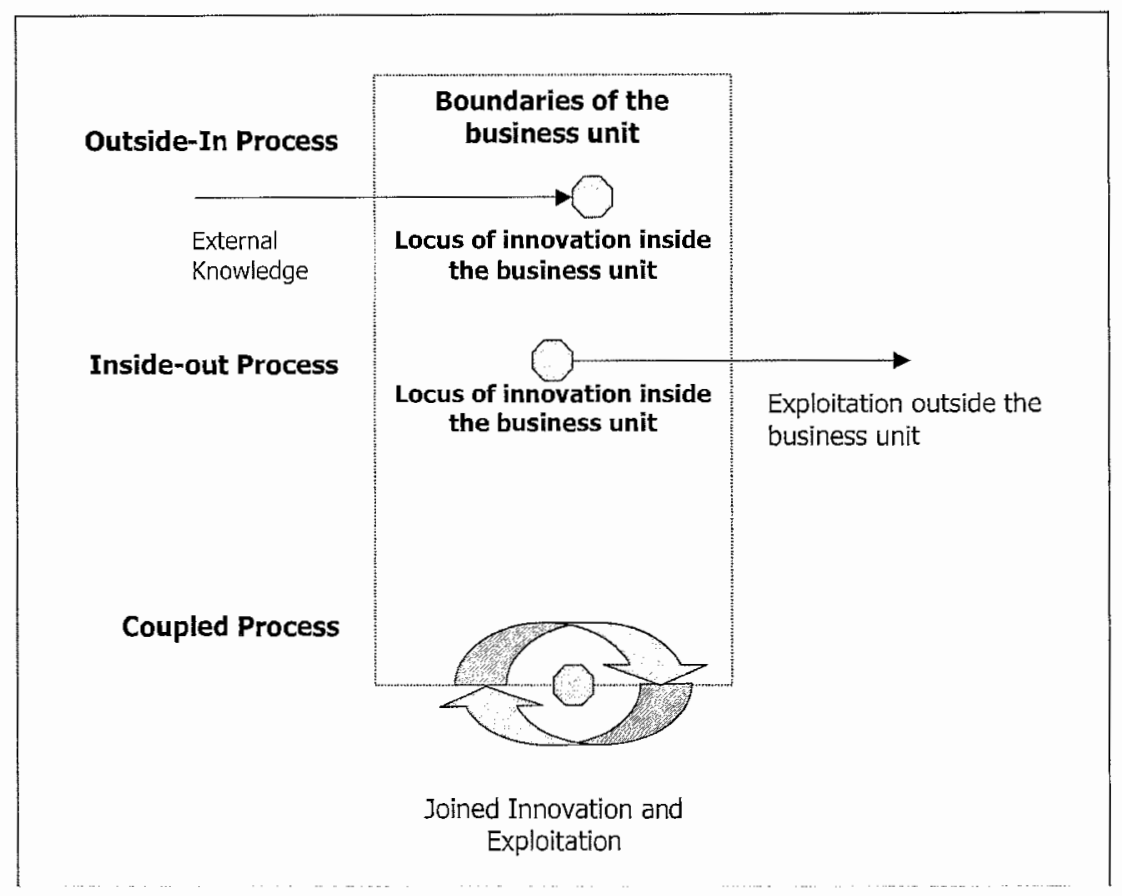

Fig. 1. Adapted Open Innovation Framework: Applying Intra-Organisatoinal Innovation Principles in Agile Software Development

\subsection{Conclusion and Implications for Future Research}

This paper explores the intra-organisational applicability and implications of open innovation in agile systems development. Additionally, it argues for a different perspective of project management that includes collaboration and knowledgesharing with other business units, customers, partners, and other relevant stakeholders pertinent to the business success of an organisation, thus embracing open innovation principles.

In terms of future research it raises a number of significant questions that could be addressed. There are many far-reaching, multi-disciplinary questions, but some of the fundamental key ones could simply seek to examine the current state of innovative collaboration between the agile team and other stakeholders outside that business unit. This analysis should go well beyond the well-established on-site customer practice that usually involves one representative, often with a very focused and myopic role within that client organization. Researchers could examine 
the extent to which various intra-organisational stakeholders are typically involved in the agile development process, and how they contribute to the innovation process on these projects. Research could also examine the current barriers to open innovation that exist in agile development and what steps 'best practice' teams are using, if any, to overcome these barriers.

The conceptual framework proposed earlier also raises some interesting research questions. In terms of 'outside-in' open innovation, how should teams choose which suppliers, customers and third parties to collaborate with? This has not been the focus of any agile development research as far as we are aware. More importantly from an agile perspective given the tight and continuous interaction between all involved, how should they choose people to represent each party, and what are the characteristics of these representatives? Furthermore in an outside-in process, integration of the external knowledge gained is vital, but this can be quite challenging in an agile environment where knowledge transfer is almost exclusively tacit. Indeed, knowledge creation and generation, applying innovation across the organization and customer and supplier integration can be difficult to achieve in such an environment. The 'inside-out' open innovation process also throws up some relevant questions. Deciding to change the locus of knowledgesharing by transferring ideas to stakeholders outside the business unit may prove challenging. Again this is exacerbated in an agile environment where explicit documentation and transfer of knowledge is usually greatly reduced. Similar to the outside-in approach, a successful inside-out approach may be contingent on the team's knowledge transfer capabilities and selection of appropriate stakeholders and their willingness and ability to engage and cooperate with the team. In relation to the 'coupled process' approach, how teams develop complementary internal value networks to create and gain external knowledge and ideas is a significant question. Where the coupled approach is enabled by a internal ecosystem or value network, there are more questions as to how the network is coordinated and maintained. Additionally, it is crucial to understand how governance is shared across the internal network and how conflict is managed if it arises. Again, agile development if particularly difficult in this case where the traditional, formal, bureaucratic role of the project manager is diminished to that of a coach. This may work well on a small co-located team within a business unit, but may be very problematic when scaled up.

Other research areas beyond the conceptual framework include the question of how an organization can successfully manage the transition to a more open form of agile innovation is one that will be addressed. In addition, who will drive and who will resist the implementation of open innovation practices in an agile environment is another interesting arena. As the agile philosophy focuses on people and their creativity, we expect that individual attitude and acceptance will almost certainly be a prerequisite for the successful implementation of open innovation practices by the firm in question. Additionally, one could examine the capabilities and requirements needed for open innovation practices to be successful. The role of the project manager can also be explored. Introducing open innovation prac- 
tices in an organisation implies change and is likely to result in uncertainty, risk and a great need for better coordination, which in turn may increase the current workload of a project manager. Indeed, identifying and engaging stakeholders in an intra-organisational network is one such challenge for the project manager. Thus, further research in this area would be beneficial in providing an insight into the role of the project manager in facilitating open innovation in a systems development environment, particularly focusing on the benefits, challenges and best practices of open innovation.

\section{References}

Abrahamsson, P., Conboy, K. and Wang, X. "Lots Done, More To Do: The Current State of Agile Systems Development Research," European Journal of Information Systems 2009, 18, pp. 1-7.

Alleman, G. "Agile Project Management Methods for IT Projects." In the Story of Manag ing Projects: A Global, Cross-Disciplinary Collection of Perspectives, Greenwood Press, Berkeley, CA, 2002.

Beck, K. Extreme Programming Explained, Addison-Wesley, 1999.

Beck, K. Extreme Programming Explained: Embrace Change. Addison-Wesley, Reading, Mass., 2000.

Beck, K. and Andres, C. Extreme Programming Explained ( $2^{\text {nd }}$ Ed). Addison Wesley, Reading, Mass., 2004.

Benbasat, I., Goldstein, D.K. and Mead, M. "The Case Research Strategy in Studies of Information Systems." MIS Quarterly, 1987, 11(3), pp. 369-386.

Brooks, Frederick P. No Silver Bullet: Essence and Accidents of Software Engineering. Reprinted in the 1995 edition of The Mythical Man-Month, 1997.

Chesbrough, H. Open Business Models: How to Thrive in the New Innovation Landscape, Boston, MA: Harvard Business School Press, 2006.

Chesbrough H. "Managing open innovation." Research \& Technology Management 2004, (47:1), pp. 23-26.

Chesbrough, H. Open Innovation: The New Imperative for Creating and Profiting from Technology, Boston, MA: Harvard Business School Press, 2003.

Chesbrough, H., Vanhaverbeke, W. and West, J. Open Innovation: Researching a New Paradigm, Oxford University Press: New York, 2006.

Conboy, K. \& Fitzgerald, B. "Method and Developer Characteristics for Effective Agile Method Tailoring: A Study of XP Expert Opinion." The Transactions on Software Engineering and Methodology (TOSEM), 2009.

Conboy, K. "Agility From First Principles: Reconstructing The Concept of Agility in Information Systems Development." Information Systems Research, 2009, 20(3), pp. 329-354

Conboy, K. "Project Failure En Mass: A Study of Budgetary Control in Systems Development Projects." European Journal of Information Systems, In Press, 2010.

Dahlander, L. Appropriating Returns from Open Innovation Processes: A Multiple Case Study of Small Firms in Open Source Software, 2004, Available at: http://opensource.mit.edu/papers/dahlander.pdf., 2004.

Dahlander, L. and Gann, D. "How Open is Innovation? " DRUID Summer Conference 2007 on Appropriability, Proximity, Routines and Innovation, Copenhagen, 2007. 
Dyba, T. \& Dingsoyr, T. "Empirical Studies of Agile Software Development: A Systematic Review." Information and Software Technology, 2008, 50, 833-859.

Elbanna, A. "Open Innovation and the Erosion of the Traditional Information Systems Project's Boundaries". Proceedings of the International Federation for Information Processing (IFIP 8.6) on Open IT-Based Innovation: Moving Towards Cooperative IT Transfer and Knowledge Diffusion, eds. León, G., Bernardos, A., Casar, J., Kautz, K., and DeGross, J. (Boston: Springer), 2008, pp. 423-439.

Farell, C., Narang, R. Kapitan, S. and Webber, H. "Towards an effective onsite customer practice. "In Proceedings of the Third International Conference on Extreme Programming and Agile Processes in Software Engineering, Alghero, Sardina, Italy (Succi, G. and Marchesi, M. Eds), 2002, pp. 52-55.

Fasnacht, D. Open Innovation in the Financial Services: Growing Through Openness, Flexibility and Customer Integration. Springer, Berlin, 2009.

Fitzgerald, B., Hartnett, G. \& Conboy, K. "Customising Agile Methods to Software Practices." European Journal of Information Systems, 2006, 15, pp. 197-210.

Foss, N.and Pedersen, T. "Transferring Knowledge in MNCs: The Roles of Sources of Subsidiary Knowledge and Organisational Context." Journal of International Management, 2002, 8, pp. 1-19.

Fowler, M. and Highsmith, J. "The Agile Manifesto." Software Development, 2001 9(8), pp. 28-32.

Gassmann, O. and Enkel, E. Towards a Theory of Open Innovation: Three core process archetypes. Available at: http://www.alexandria,unisg.ch/Publikationen/274, 2004.

Glaser, B.G. Basics of grounded theory analysis: Emergence vs. Forcing. Mill Valley, CA: Sociology Press, 1992.

Griffin, L. "A Customer Experience: Implementing XP." In XP Universe Raleigh, NC, July $23^{\text {nd }}-25^{\text {th }}$ (Wells, D. Ed), 2001, pp. 195-200.

Hamel, G. and Prahalad, C.K. "Strategic Intent." Harvard Business Review, 1989, MayJune.

Kane, H.C.M. and Ragsdell, G. "How Might Models of Innovation Inform the Management of Knowledge." KMSS Proceedings, 2003.

Lagerstrom, K. and Andersson, M. "Creating and Sharing Knowledge within a Transnational Team - The Development of a Global Business System." Joumal of World Business, 2003, 38(2), pp. 84-95.

Lindstrom, L. and Jeffries, R. "Extreme Programming and Agile Software Development Methodologies." Information Systems Management, 2004, 21(3) pp. 41-52.

Miles, M. and Huberman, A. Qualitative Data Analysis. Sage, London, 1999.

Nerur, S., Mahapatra, R. and Mangalara, G. "Challenges of Migrating to Agile Methodologies." Communication of he ACM, 2005, 48(5), pp. 72-78.

Oppenheim, A. Questionnaire Design, Interviewing and Attitude Measurement. Continuum, New York, 1992.

Potter, J. Discourse Analysis as a Way of Analysing Naturally Occuring Talk. In Qualitative Research, Theory, Method and Practice (Silvermann, D., Ed.), Sage Publications, London, 1999, pp. 144-160.

Rubin, H. and Rubin, I. Qualitative Interviewing: The Art of Hearing Data. Sage, Thousand Oaks, CA, 2005.

Schwaber, K. and Beedle, M. Agile software development with SCRUM, Prentice Hall, 2002.

Stake, R.E. "Case studies." In Handbook of Qualitative Research (in Denzin, N.K., Lincoln, Y.S. Eds), Sage Publications, Thousand Oaks, 2000, pp. 435-454. 
Stapleton, L. "Ethical decision making in technology development: a case study of participation in a large-scale information systems development project." AI and Society, 2008, 22(3), pp. 405-429

Strauss, A. and Corbin, J. Basics of Qualitative Research: Grounded Theory Procedures and Techniques. 1990, Sage Publications, Newbury Park, CA, 1990.

Strauss, A. and Corbin, J. Basics of Qualitative Research: Grounded Theory Procedures and Techniques ( $2^{\text {nd }}$ Ed), Sage Publications, Newbury Park, CA, 1998.

Tapscott, D. and Williams, A. Realising the Power of Innovation Webs, Optimizemag.com, December (http://www.cioindex.com/nm/articlefiles/2776Optimize InnovationWebs.pdf, 2005.

Trauth, E. and O'Connor, M. "A study of the interaction between information technology and society: An illustration of combined qualitative research methods." In Nissen, H.E., Klein, H.K. and Hirschheim, R. (Eds) Information Systems Research: Contemporary Approaches and Emergent Traditions, 1991, 131-144. Amsterdam: North-Holland.

Tsai, W. and Ghoshal,, S. "Social Capital and Value Creation: The Role of Intrafirm Networks." Academy of Management Journal, 1998, 41(4), pp. 464-76.

Vanhaverbeke, W. "The Interorganisational Context of Open Innovation. "In Open Innovation: Researching a New Paradigm, Chesbrough, H., Vanhaverbeke, W. and West, J., Eds., Oxford University Press: London, 2006.

Wengraf, T. Qualitative research interviewing: biographic narrative and semi-structured method, London: Sage Publications, 2001.

West, J. and Gallagher, S. "Challenges of open innovation: the paradox of firm investment in open-source software." $R \& D$ Management, 2006, (36:3), pp. 319-331.

West, J. and Gallagher, S. "Patterns of Open Innovation in Open Source Software." In Open Innovation: Researching a New Paradigm, Chesbrough, H., Vanhaverbeke, W and West, J., Eds, Oxford University Press, 2006.

\section{Author Biographies}

Kieran Conboy is a lecturer in information systems at the National University of Ireland Galway. His research focuses on agile systems development approaches as well as agility across other disciplines. Kieran is currently involved in numerous national and international projects in this area, and has worked with many companies on their agile initiatives including Intel, Microsoft, Accenture, HP, and Fidelity Investments. Kieran has chaired related conferences including the European Conference in Information Systems (Galway 2008) the XP and Agile Development Conference (Limerick 2008) and also has chairing roles at XP2009 and $\mathrm{XP2010}$. Some of his research has been published in various leading journals and conferences such as Information Systems Research, the European Journal of Information Systems, the International Conference in Information Systems (ICIS), the European Conference in Information Systems (ECIS), IFIP 8.6 and the XP200n conference series. He is also associate editor of the European Journal of Information Systems. Prior to joining NUI Galway, Kieran was a management consultant with Accenture, where he worked on a variety of projects across Europe and the US. Kieran can be reached at kieran.conboy@nuigalway.ie. 
Lorraine Morgan works as a researcher with Lero, the Irish Software Engineering Research Centre at the University of Limerick. Her research focuses on agile methods and open innovation, open business models, value networks and open source software. In addition, some of her research has been published in journals and conferences such as Database for Advances in Information Systems, European Conference of Information Systems (ECIS), International Federation for Information Processing (IFIP) Working Conference 8.6 and 8.2 and the International Open Source Systems Conference. Lorraine can be reached at lorraine.morgan@ul.ie.

\section{Acknowledgements}

This work is supported in part by Science Foundation Ireland grant 03/CE2/1303_1 to Lero - the Irish Software Engineering Research Centre. 